\title{
PENGARUH INTERVENSI PENDIDIKAN KESEHATAN REPRODUKSI DENGAN METODE PEER GROUP TERHADAP KONSEP DIRI REMAJA DI MAN 1 KOTA TERNATE
}

\section{THE EFFECT OF INTERPRENTION OF REPRODUCTIVE HEALTH EDUCATION USING PEER GROUP METHODS ON SELF-CONCEPT IN MAN 1 TERNATE CITY}

\author{
Sri Linda \\ Program Studi Diploma III Kebidanan Politeknik Kesehatan Kementerian Kesehatan Ternate \\ Korespondensi: srilinda1989@gmail.com
}

\begin{abstract}
The adolescent is a transition period that connects between the period of the child to the adult period, so that requires special attention and protection. During puberty, adolescents are susceptible to problems related to sexual and reproductive health. Problems that occur can be related to the way teenagers maintain themselves to remain healthy in reproduction or also in maintaining behavior so as not to engage in risky activities. In adolescence, there are several developments, one of which is the development of self-concept. At the age of adolescents with high school education levels included in the stages of late adolescence (late adolescence) who have characteristics closer to peers. Handling to prevent adolescent reproductive health problems is through four approaches, namely institutions, families, peer groups, and workplaces. The strong influence of peer groups is because adolescents are more outside the house with peers as a group, so it can be understood that peer influence on attitudes, speech, interests, appearance, and behavior is greater than family influence. This study aims to determine the effect of reproductive health education interventions with the peer group method on adolescent self-concept. This study is a quasi-experimental (Quasy Experimental) using a one-group design pattern with measurements of pre-test and post-test (one group pretest-posttest design). Get the difference between the mean self-concept scores in the pre-test and post-test groups with a pvalue of 0.001 .
\end{abstract}

Keywords : Reproductive Health, Self Concept, Peer Group Method, Youth

\begin{abstract}
ABSTRAK
Remaja merupakan masa transisi yang menghubungkan antara periode anak menuju periode dewasa, sehingga memerlukan perhatian dan perlindungan yang khusus. Selama pubertas, remaja rentan mengalami permasalahan yang berkaitan dengan kesehatan reproduksi dan seksual. Permasalahan yang terjadi bisa berkaitan dengan cara remaja menjaga diri agar tetap sehat secara reproduksi ataupun juga dalam menjaga perilaku agar tidak melakukan aktivitas yang beresiko. Pada masa remaja terdapat beberapa perkembangan, salah satunya adalah perkembangan konsep diri. Pada usia remaja dengan tingkat pendidikan SMA termasuk dalam tahapan remaja akhir (late adolescence) yang memiliki ciri-ciri lebih dekat dengan teman sebaya.
\end{abstract}


Penanganan yang dilakukan untuk mencegah masalah kesehatan reproduksi remaja adalah melalui empat pendekatan yaitu institusi, keluarga, kelompok sebaya (peer group), dan tempat kerja. Kuatnya pengaruh kelompok sebaya (peer group) dikarenakan remaja lebih banyak berada diluar rumah bersama dengan teman sebaya sebagai kelompok, maka dapatlah dimengerti bahwa pengaruh teman sebaya pada sikap, pembicaraan, minat, penampilan, dan perilaku lebih besar dari pada pengaruh keluarga. Penelitian ini bertujuan mengetahui pengaruh intervensi pendidikan kesehatan reproduksi dengan metode peer group terhadap konsep diri remaja. Penelitian ini merupakan eksperimen semu (Quasy Experimental) menggunakan pola rancangan satu kelompok dengan pengukuran pre test dan post test (one group pretest posttest design). Ditemukan perbedaan yang bermakna secara statistik dengan rerata skor konsep diri pada kelompok pre test dan post test dengan p-value 0.001 .

\section{Kata kunci: Kesehatan Reproduksi, Konsep Diri, Metode Peer Group, Remaja}

\section{PENDAHULUAN}

Remaja merupakan masa transisi yang menghubungkan antara periode anak menuju periode dewasa, sehingga memerlukan perhatian dan perlindungan yang khusus (Health for the world's adolescent, 2014). International Conference on Population (ICPD) di Kairo tahun 1994, menyatakan bahwa kesehatan reproduksi remaja perlu mendapatkan perhatian khusus secara global, karena pada masa remaja muncul berbagai masalah akibat ketidaktahuan terhadap tindakan yang harus dilakukan sehubungan dengan perkembangan yang sedang dialami, khususnya masalah kesehatan reproduksi yang masih minim (Rahmawati D, 2013). Berdasarkan data dari World Health Organization (WHO) pada tahun 2012 kelompok remaja di dunia diperkirakan berjumlah 1,2 milyar atau $18 \%$ dari jumlah penduduk dunia (Waddington, 2015).

Estimasi jumlah penduduk Indonesia menurut umur dan jenis kelamin tahun 2016 yaitu 10-14 tahun (laki-laki 11.571.921 jiwa dan perempuan 11.005.173 jiwa), 15-19 tahun (laki-laki 11.335.656 jiwa dan perempuan 10.825.295 jiwa), dan 20-24 tahun (laki-laki 10.911.703 jiwa dan perempuan 10.657.300 jiwa). Sedangkan estimasi jumlah penduduk menurut jenis kelamin di Provinsi Maluku Utara tahun 2016, laki-laki sebanyak 605.068 jiwa dan perempuan 580.844 jiwa (Pusat data dan informasi, Kementerian Kesehatan RI, 2016).

Remaja mengalami proses peralihan dari masa anak-anak menuju masa dewasa yang ditandai dengan pertumbuhan dan perkembangan pesat aspek biologis, psikologis, kognitif dan sosial emosional 
(Curtis AC, 2015). Ciri lain pada remaja adalah proses kematangan organ reproduksi yang disebut dengan pubertas (Wahba M, 2012). Selama pubertas, remaja rentan mengalami permasalahan yang berkaitan dengan kesehatan reproduksi dan seksual. Permasalahan yang terjadi bisa berkaitan dengan cara remaja menjaga diri agar tetap sehat secara reproduksi ataupun juga dalam menjaga perilaku agar tidak melakukan aktivitas yang beresiko (World Health Organization, 2010).

Banyak remaja yang mencapai usia kedewasaan tanpa persiapan sehingga menyebabkan mereka mengalami konflik dan kebingungan terkait dengan seksualitas. Hal ini dikarenakan topik kesehatan reproduksi dan seksual masih menjadi hal yang tabu untuk dibicarakan dengan orang dewasa, termasuk orang tua dan guru (Ramayanti D, 2015). Pengetahuan kesehatan reproduksi dan seksual remaja saat ini sering tidak tepat. Tidak jarang pengetahuan yang diperoleh hanyalah sebatas informasi, bukan berupa pendidikan. Sehingga masalah penyimpangan yang terjadi semakin mengkhawatirkan yang mana disebabkan pengetahuan remaja tentang seksualitas masih cukup rendah, kemudian tidak adanya sensor dalam dirinya sendiri terhadap rangsangan dari luar (Sarwono, Sarlito W, 2011).

Intervensi untuk mengatasi permasalahan kesehatan reproduksi remaja khususnya pada negara berkembang dikategorikan berdasarkan setting program, yaitu program berbasis sekolah, media massa, komunitas, tempat kerja dan fasilitas kesehatan. Intervensi berbasis sekolah meskipun memiliki dampak yang tidak terlalu cepat tetapi merupakan salah satu upaya yang efektif karena memiliki cakupan yang luas dan terarah (Speizer IS, 2003). Disamping itu remaja lebih banyak menghabiskan sebagian besar waktunya di sekolah, dalam kegiatan belajar mengajar terutama dalam pergaulan di lingkungan sekolah. Pendapat bahwa pendidikan kesehatan reproduksi di sekolah akan menyebabkan perilaku seksual siswa menjadi lebih bebas merupakan hal yang tidak tepat. Hasil penelitian menyimpulkan bahwa siswa yang menerima pendidikan kesehatan reproduksi menjadi lebih bertanggung jawab terhadap perilaku seksual dan mereka mampu menunda dalam memulai hubungan seksual (Utomo ID, 2010). Pendidikan kesehatan reproduksi dan seksual ini bermaksud untuk menerangkan segala hal yang berhubungan dengan 
reproduksi, seks dan seksualitas dalam bentuk yang wajar, yang meliputi proses terjadinya pembuahan, kehamilan sampai kelahiran, penjelasan anatomi manusia, pertumbuhan dan perkembangan organorgan reproduksi, perilaku seksual, aspekaspek kesehatan, kejiwaan dan kemasyarakatan sesuai dengan norma-norma yang berlaku di masyarakat (Sarwono, Sarlito.W. 2011).

Hal yang melatarbelakangi pemberian pendidikan kesehatan reproduksi di sekolah selain karena remaja lebih banyak menghabiskan waktunya di sekolah. Pada masa remaja terdapat beberapa perkembangan, salah satunya adalah perkembangan konsep diri yang merupakan semua perasaan dan pemikiran seseorang mengenai dirinya sendiri. Remaja pada masa transisi ini seringkali dihadapkan pada situasi yang membingungkan, di satu pihak mereka masih anak-anak dan di lain pihak harus bersikap sebagai orang dewasa. Situasi seperti ini dapat menimbulkan konflik dan menyebabkan perubahan pada tingkah laku remaja, yang apabila tidak dikontrol dapat menimbulkan permasalahan (Kusmiran E, 2011). Pada usia remaja dengan tingkat pendidikan SMA termasuk dalam tahapan remaja akhir (late adolescence) yang memiliki ciri-ciri lebih dekat dengan teman sebaya. Selain guru yang dapat memberikan pendidikan kesehatan reproduksi dan seksual, remaja juga dapat memperoleh informasi tersebut dari teman sebayanya (Pinem, Saroha, 2009).

Dikutip dari Moeliono, 2014 bahwa faktor-faktor yang memengaruhi keadaan kesehatan reproduksi remaja adalah faktor internal antara lain pengetahuan, sikap, konsep diri remaja itu sendiri dan faktor eksternal yaitu lingkungan dimana remaja berada memengaruhi kegiatan seksual remaja yang berisiko terhadap masalah kesehatan reproduksi (Suriani, Hermansyah, 2014). Menurut penelitian yang dilakukan oleh Suriani dan Hermansyah tahun 2014 bahwa penanganan yang dilakukan untuk mencegah masalah kesehatan reproduksi remaja adalah melalui empat pendekatan yaitu institusi, keluarga, kelompok sebaya (peer group), dan tempat kerja. Kuatnya pengaruh kelompok sebaya (peer group) dikarenakan remaja lebih banyak berada diluar rumah bersama dengan teman sebaya sebagai kelompok, maka dapatlah dimengerti bahwa pengaruh teman sebaya pada sikap, pembicaraan, minat, penampilan, dan perilaku lebih besar dari pada pengaruh keluarga. 
Madrasah Aliyah Negeri 1 Kota Ternate merupakan salah satu sekolah dengan jenjang pendidikan menengah pada pendidikan formal di Kota Ternate setara dengan menengah atas. MAN 1 Kota Ternate mempunyai empat jurusan yaitu Ilmu Alam, Ilmu Sosial, Ilmu Keagamaan, dan Bahasa. MAN 1 Kota Ternate memiliki beberapa organisasi diantaranya Organisasi Siswa Intra Sekolah (OSIS), Praja Muda Karana (Pramuka), Palang Merah Remaja (PMR) dan satu organisasi yang berkaitan dengan kesehatan reproduksi remaja di MAN 1 Kota Ternate yaitu Pusat Informasi dan Konseling Kesehatan Reproduksi Remaja (PIK KRR), sehingga untuk mendapatkan informasi kesehatan reproduksi di sekolah berasal dari guru mata pelajaran dan konsultasi dari anggota PIK KRR akan tetapi kebanyakan hanya seputar masalah akademik dan pribadi. Berdasarkan data hasil wawancara pada 10 siswa-siswi MAN 1 Kota Ternate didapatkan hasil 2 orang cukup mengetahui tentang kesehatan reproduksi dan 8 orang yang belum mengetahui tentang kesehatan reproduksi.

\section{METODE}

Penelitian ini merupakan eksperimen semu (Quasy Experimental) menggunakan pola rancangan satu kelompok dengan pengukuran pre test dan post test (one group pretest posttest design). Populasi adalah keseluruhan dari subjek yang akan diteliti. Populasi dalam penelitian ini adalah seluruh siswa MAN 1 Kota Ternate. Populasi target adalah siswa-siswi MAN 1 Kota Ternate kelas X, XI, XII Jurusan IPA dan IPS. Sedangkan populasi terjangkau adalah siswa-siswi MAN 1 Kota Ternate kelas XI Jurusan IPA 1 dan IPA 2. Sampel pada penelitian ini adalah siswa-siswi MAN 1 Kota Ternate kelas XI Jurusan IPA 1 dan IPA 2 yang berjumlah 36 orang dengan menggunakan rumus Lemeshowb, yang memenuhi kriteria inklusi dan tidak termasuk dalam kriteria eksklusi. Pengambilan data pada variabel intervensi pendidikan kesehatan reproduksi dengan metode peer group dan konsep diri remaja ini menggunakan kuisioner. Analisis data menggunakan uji T berpasangan. Penelitian ini dilakukan setelah mendapatkan izin kelayakan dari komisi etik penelitian kesehatan Poltekkes Kemenkes Tanjung Karang. Penelitian ini menerapkan tiga prinsip dasar etika penelitian, yaitu respect to person, beneficence and non maleficence serta justice.

\section{HASIL DAN PEMBAHASAN}

Penelitian ini dilakukan terhadap siswasiswi kelas XI IPA 1 dan IPA 2 MAN 1 
Kota Ternate yang memenuhi kriteria inklusi dan eksklusi.

1. Karakteristik Subjek Penelitian
Subjek dalam penelitian ini adalah siswa-siswi kelas XI IPA 1 dan IPA 2 MAN 1 Kota Ternate.

Tabel 1 Karakteristik subjek penelitian

\begin{tabular}{ccc}
\hline Umur & Frekuensi (f) & Persentase (\%) \\
\hline 16 tahun & 12 & 33 \\
15 tahun & 14 & 39 \\
14 tahun & 10 & 28 \\
\hline Jumlah (n) & 36 & 100 \\
\hline
\end{tabular}

Tabel 1 menggambarkan karakteristik subjek penelitian/responden pada usia 14-16 tahun. Hal ini sesuai dengan tahapan remaja pada tingkat pendidikan SMA yaitu remaja tengah (Middle
Adolescence) 13-15 tahun dan remaja akhir (Late Adolescence) 16-19 tahun.

2. Konsep Diri Remaja Berkaitan dengan

Kesehatan Reproduksi

Tabel 2 Konsep Diri Remaja pada Kelompok Pre Test dan Post Test

\begin{tabular}{lcccc}
\hline \multirow{2}{*}{$\begin{array}{c}\text { Konsep } \\
\text { Diri }\end{array}$} & \multicolumn{2}{c}{ Pre Test } & \multicolumn{2}{c}{ Post Test } \\
\cline { 2 - 5 } & Frekuensi (f) & $\begin{array}{c}\text { Persentase } \\
(\boldsymbol{\%})\end{array}$ & $\begin{array}{c}\text { Frekuensi } \\
(\mathbf{f})\end{array}$ & $\begin{array}{c}\text { Persentase } \\
(\boldsymbol{\%})\end{array}$ \\
\hline Positif & 22 & 61 & 29 & 81 \\
Negatif & 14 & 39 & 7 & 19 \\
\hline Jumlah & 36 & 100 & 36 & 100 \\
\hline
\end{tabular}

Tabel 2 menggambarkan bahwa kelompok pre test yang memiliki konsep diri positif sebanyak $61 \%$ dan konsep diri negatif sebanyak 39\%, sedangkan post test yang memiliki konsep diri positif sebanyak $81 \%$ dan konsep diri negatif sebanyak 19\%, yang mana materi dalam buku bacaan siswa mengenai kesehatan reproduksi remaja dibahas secara keseluruhan oleh kelompok sebaya (peer group).

3. Pengaruh Intervensi Pendidikan Kesehatan Reproduksi dengan Metode Peer Group terhadap Konsep Diri Remaja

Tabel 3 Perbandingan skor sebelum dan sesudah intervensi pendidikan kesehatan reproduksi dengan metode peer group

\begin{tabular}{lcc}
\hline \multirow{2}{*}{ Konsep Diri } & \multicolumn{2}{c}{ Kelompok } \\
\cline { 2 - 3 } & Pre Test & Post Test \\
\hline Mean (X) & 285,44 & 295,72 \\
Standar Deviasi (SD) & 13,913 & 10,525 \\
Rentang & $250-311$ & $280-312$ \\
\hline Nilai p* & \multicolumn{2}{c}{0,001} \\
\hline Keterangan: *Uji T berpasangan & \multicolumn{2}{c}{}
\end{tabular}


Hasil penelitian sebagaimana tercantum dalam Tabel 3 ditemukan perbedaan yang bermakna secara statistik dengan rerata skor konsep diri pada kelompok pre test dan post test $(\mathrm{p}<0,05)$.

\section{Pengaruh Intervensi Pendidikan}

Kesehatan Reproduksi dengan Metode Peer Group terhadap Konsep Diri Remaja

Pemberian intervensi pendidikan kesehatan reproduksi dengan metode peer group yang telah dilaksanakan di MAN 1 Kota Ternate terhadap siswa-siswi kelas XI IPA memiliki peranan yang cukup berarti dalam meningkatkan konsep diri remaja. Metode peer group ini dapat meningkatkan konsep diri remaja dilihat pada hasil yang signifikan $(\mathrm{p}<0,05)$.

Hal ini karena metode peer group atau teman sebaya merupakan tempat di mana remaja sering berkumpul untuk mendiskusikan suatu masalah baik masalah yang menyenangkan atau menyedihkan yang dapat dipercaya. Disamping itu teman sebaya juga selalu melakukan perilaku tolong menolong, kerja sama walaupun ada yang melakukan persaingan karena berbeda minat atau keinginan (Utami AD, 2016). Peer group adalah kelompok teman sebaya yang sukses di mana ia dapat berinteraksi. Dalam kelompok teman sebaya (peer group), individu merasakan adanya kesamaan satu dengan yang lainnya seperti usia, kebutuhan dan tujuan yang dapat memperkuat kelompok tersebut. (Asmara T, 2007)

Konsep diri merupakan gambaran yang dimiliki seseorang tentang dirinya, yang dibentuk melalui pengalaman-pengalaman yang diperoleh dari interaksi dengan lingkungan. Konsep diri bukan merupakan faktor bawaan, melainkan berkembang dari pengalaman yang terus menerus dan terdiferensiasi (Yapono F, 2013). Pengalaman yang didapatkan oleh siswasiswi kelas XI IPA MAN 1 Kota Ternate ini dengan cara belajar melalui metode peer group, yang didalam proses pembelajarannya siswa-siswi ini saling bertanya, menceritakan pengalaman, berbagi informasi sehingga memberikan dampak yang positif pada dirinya. Peer group diharapkan mampu tumbuh menjadi peer educator yang diharapkan dapat membahas dan menangani permasalahan kesehatan reproduksi remaja. Institusi sekolah merupakan jalur yang sangat potensial untuk melatih peer group ini, karena institusi sekolah sangat memengaruhi kehidupan dan pergaulan remaja. Pendidikan kesehatan dengan peer group mempunyai kelebihan yakni pendekatan yang dilakukan oleh peer educator kepada teman sebayanya yang berorientasi pada keinginan teman sebayanya dan juga bersifat informal. Keadaan ini mendukung untuk terciptanya 
proses pembelajaran yang menyenangkan antara peer educator kepada teman sebayanya dalam suasana informal membuat suasana pembelajaran tidak membosankan dan merangsang untuk bebas bertanya. Hal ini didukung dengan penelitian yang dilakukan oleh Simbolon (2008) yang berjudul pendidikan kesehatan melalui teman sebaya dalam meningkatkan pengetahuan remaja tentang pencegahan kehamilan tak diinginkan (KTD) yang menyatakan bahwa terjadinya peningkatan pengetahuan pada remaja adalah karena dengan metode pendidikan teman sebaya, remaja tidak merasa malu untuk bercerita dengan teman sebayanya. Selain itu teman sebaya berperan sebagai role model bagi temannya. Penelitian oleh Utami D, dkk (2014) yang menyatakan bahwa peer group memberikan pengaruh yang positif terhadap remaja yang diteliti, terbukti dengan adanya peningkatan pengetahuan, sikap dan akhirnya diwujudkan melalui tindakan. Hasil pendidikan kesehatan peer group dalam memberikan informasi kesehatan selain meningkatkan pengetahuan juga meningkatkan sikap remaja putri dalam berperilaku. Peningkatan sikap pada responden ini juga dilihat pada hasil penelitian Hartoyo (2013) yang menyimpulkan bahwa metode peer group lebih efektif dalam meningkatkan perilaku dan sikap remaja terhadap NAPZA. Peer educator merupakan metode pemberian edukasi di mana pemberi informasi adalah teman sebaya. Sehingga kelompok teman sebaya sebagai lingkungan sosial pada tahap remaja mempunyai peranan yang cukup penting bagi perkembangan kepribadiannya. (Desmarinta U, Djuwitaningsih S, Rochimah, 2014)

Menurut Hetherintong dan Pareke (2003) bahwa teman sebaya merupakan peran yang sangat banyak terhadap remaja. Perannya antara lain sebagai penguat dalam menginginkan sesuatun misalnya mendapat pujian, sebagai model untuk dapat dicontoh, memiliki hubungan yang kuat dengan harga diri melalui perbandingan terhadap nilainilai dan sebagai penunjuk untuk menumbuhkan rasa kebersamaan. Sehingga dapat dipahami bahwa peer group atau teman sebaya pada remaja merupakan kelompok yang terjalin hubungan erat dan tinggi berdasarkan kepentingan, minat secara pribadi. Disamping itu, tempat mencurahkan atau mendiskusikan permasalahan yang dihadapi namun tidak ditemukan di rumah. Apabila dihubungkan dengan kebutuhan kesehatan reproduksi untuk mudah dipahami oleh remaja sangat baik sekali dengan menggunakan metoda peer group, karena usia responden berada dalam rentang usia remaja. (Desmarinta U, Djuwitaningsih S, Rochimah, 2014) 
Konsep diri bukanlah merupakan aspek yang dibawa sejak lahir, tetapi merupakan aspek yang dibentuk melalui interaksi individu dalam berbagai lingkungan, baik itu lingkungan keluarga maupun lingkungan lain yang lebih luas. Pada dasarnya konsep diri seseorang terbentuk dari lingkungan pertama yang paling dekat dengan individu, yaitu lingkungan keluarga, tetapi lamakelamaan konsep diri individu akan berkembang melalui hubungan dengan lingkungan yang lebih luas, seperti teman sebaya, lingkungan masyarakat dan sebagainya. Hasil dari interaksi individu dengan lingkungan inilah yang lebih memberikan pengaruh yang besar terhadap konsep diri individu tersebut, terutama pengaruh kelompok teman sebaya (peer group). Jika dalam perkembangannya individu mempunyai konsep diri yang positif, maka individu tersebut cenderung memandang kehidupannya dengan sikap yang positif, begitu juga sebaliknya individu yang mempunyai konsep diri yang negatif akan memandang kehidupannya dengan sikap-sikap yang negatif, sehingga konsep diri individu yang positif maupun negatif tersebut akan berpengaruh terhadap pembentukan sikap dan perilaku individu tersebut. Konsep diri positif maupun negatif pada remaja bisa saja terbentuk karena adanya faktor internal dan keadaan keluarga yang juga merupakan lingkungan awal dalam membentuk konsep diri anak. Oleh karena itulah individu perlu untuk mengembangkan dan mempunyai konsep diri yang positif untuk dapat mengembangkan konsep diri yang positif tersebut maka diperlukan bimbingan dan pembinaan yang baik dari lingkungan keluarga, lingkungan sekitar dan lingkungan dalam pergaulan dengan teman sebayanya. (Asmara T, 2007)

Pada masa remaja pengaruh kelompok sangatlah kuat. Mereka cenderung untuk berkumpul dan berinteraksi dalam kelompok sebayanya. Dengan adanya dinamika dan pengaruh dalam kelompok, remaja dapat merumuskan, memperbaiki dan meningkatkan konsep dirinya melalui kelompok yang dimilikinya. Sehingga dengan adanya interaksi dan dinamika yang berkembang dalam kelompok (peer group) itulah yang pada akhirnya akan membentuk konsep diri pada remaja. (Asmara T, 2007)

\section{SIMPULAN}

Berdasarkan hasil dan pembahasan dapat disimpulkan bahwa pemberian intervensi pendidikan kesehatan reproduksi dengan metode peer group yang dilaksanakan pada penelitian ini merupakan upaya yang cukup efektif untuk meningkatkan konsep diri remaja dengan 
indikator hasil pengujian hipotesis yaitu terdapat pengaruh pengaruh intervensi pendidikan kesehatan reproduksi dengan metode peer group terhadap konsep diri remaja.

\section{UCAPAN TERIMA KASIH}

Program Studi Diploma III Kebidanan Politeknik Kesehatan Kementerian Kesehatan Ternate

\section{DAFTAR RUJUKAN}

Agustiani, H. (2006), Psikologi perkembangan pendekatan ekologi kaitannya dengan konsep diri dan penyesuaian diri pada remaja, PT Refika Aditama, Bandung.

Asmara, T. (2007), Efektivitas bimbingan kelompok dengan teknik peer group dalam meningkatkan konsep diri siswa kelas III A di SMP Mardisiswa 1 Semarang. Jurusan Bimbingan Dan Konseling Fakultas Ilmu Pendidikan Universitas Negeri Semarang.

Curtis AC. (2015), Defining adolesence. Journal of adolescent and family health. University of San Francisco, accurtis@usfca.edu, $\quad$ vol.7(issue 2) article 2, h.1-3.
Dahlan, M.S. (2011), Statistik untuk Kedokteran dan Kesehatan Edisi 5, Salemba Medika, Jakarta.

Desmarinta U, Djuwitaningsih S, Rochimah (2014), Pengaruh pendidikan kesehatan metode peer group terhadap pengetahuan dan sikap remaja putri tentang kesehatan reproduksi. Jurusan Keperawatan Poltekkes Kemenkes Jakarta III. JKep. Vol. 2(3), Nopember 2014, h. 55-62.

Health for the world's adolescents. A second chance in the second decade. World Health Organization. (2014). h.1-20.

Hidayat, A.AA. (2014), Metode Penelitian Kebidanan dan Teknik Analisis Data, Salemba Medika, Jakarta.

Kusmiran E. (2011), Kesehatan Reproduksi Remaja dan Wanita, Salemba Medika, Jakarta.

Nurihsan, AJ dan Agustin, Mubiar. (2011), Dinamika Perkembangan Anak dan Remaja Tinjauan Psikologi, Pendidikan, dan Bimbingan, PT Refika Aditama, Bandung. 
Peraturan Pemerintah Republik Indonesia No 61 tahun 2014 tentang Kesehatan Reproduksi. PP RI No.61(2014).

Pinem, Saroha. (2009), Kesehatan Reproduksi dan Kontrasepsi, TIM, Jakarta.

Pusat data dan informasi, Kementerian Kesehatan RI. (2016).

Ramayanty D, Sanusi SR, Fitria M. (2015), Hubungan pengetahuan dan sikap remaja tentang kesehatan reproduksi dengan perilaku seksual di SMA Bayu Pertiwi Sunggal. Alumni Mahasiswa Departemen Kependudukan dan Biostatistik FKM-USU.

Rahmawati D. (2013), Integrasi pendidikan kesehatan reproduksi pada pembelajaran biologi di SMA dengan penerapan kurikulum 2013. Jurusan Biologi Universitas Negeri Padang.

Sarwono, Sarlito W. (2011), Psikologi Remaja Edisi Revisi, Rajawali Pers Citra Niaga Buku Perguruan Tinggi, Jakarta.

Speizer IS, Magnani RJ, Colvin CE. (2003), The Effectiveness of Adolescent
Reproductive Health Interventions in Developing Countries: A Review of the Evidence. Journal Of Adolescent Health, no.33, h.324-348.

Suriani, Hermansyah. (2014), Pengaruh peer group terhadap peningkatan pengetahuan kesehatan reproduksi remaja, Jurnal Ilmu Keperawatan. ISSN:2338-6371.

Utami AD. (2016), Pengaruh pendidikan kesehatan peer group terhadap perilaku SADARI pada remaja putri di dusun Celungan Sumberagung Moyudan Sleman. Program Studi Ilmu Keperawatan Fakultas Ilmu Kesehatan Universitas Aisyiyah Yogyakarta.

Utomo ID, McDonald P, Hull T. (2010), Meningkatkan Pendidikan Kesehatan Reproduksi dalam Kurikulum Nasional Indonesia. Gender and Reproductive Health Study. Policy Brief No. 2.

Waddington C dan Sambo C. (2015), Financing health care for adolescents: a necessary part of universal health coverage. Bull World Health Organ, no. 93, h.57-9. 
Wahba M, Roudi-Fahmi F. (2012), Policy brief. The need for reproductive health education in schools in egypt. PRB Inform empower advance, October.

WHO. (2006), Sexual and reproductive health, diakses dari www.who.org.

World Health Organization. (2010), Developing sexual health programmes. A framework for action.

Yapono F. (2013), Konsep-Diri, Kecerdasan Emosi Dan Efikasi-Diri. Humanitas. September vol.2, no.3. h.208-16 